\title{
Erratum to: A Framework for Measurement Feedback to Improve Decision-Making in Mental Health
}

Edward Seidman $\cdot$ Bruce F. Chorpita $\cdot$

William E. Reay · Wayne Stelk • Ann F. Garland •

Krista Kutash · Charlotte Mullican · Heather Ringeisen

Published online: 24 February 2010

(C) Springer Science+Business Media, LLC 2010

\section{Erratum to: Adm Policy Ment Health}

DOI 10.1007/s10488-009-0260-9

The following disclaimer should have appeared in this article:
The online version of the original article can be found under doi:10.1007/s10488-009-0260-9.

\section{E. Seidman $(\square)$}

William T. Grant Foundation and New York University,

570 Lexington Avenue, 18th Floor, New York,

NY 10022, USA

e-mail: eseidman@wtgrantfdn.org; edward.seidman@nyu.edu

\section{B. F. Chorpita}

University of California, Los Angeles, CA, USA

W. E. Reay

OMNI Behavioral Health and Northcentral University,

Omaha, NE, USA

W. Stelk

Massachusetts Behavioral Health Partnership/ValueOptions,

Boston, MA, USA
The opinions expressed in this paper are those of the author and do not reflect the official position of the Agency for Healthcare Research and Quality or the US Department of Health and Human Services.

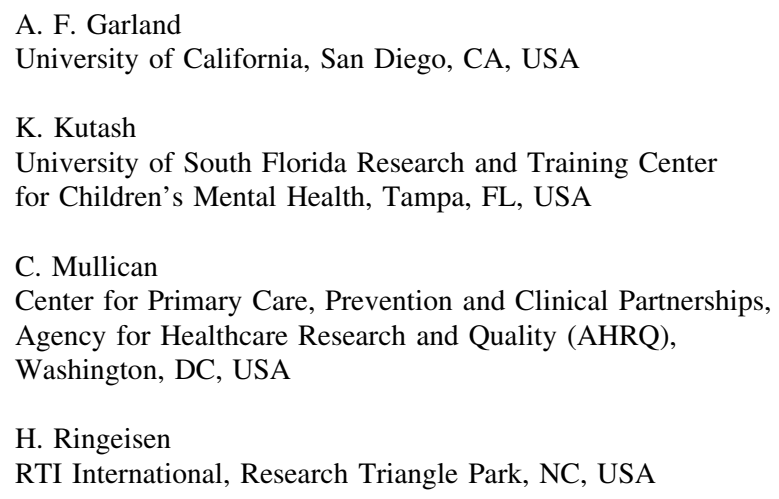

